\title{
Integrate for car brake failure and engine overheat system
}

\author{
G. Subhashini, Anas Aiman Albanna, Raed Abdulla \\ School of Engineering, Asia Pacific University of Technology and Innovation (APU), Technology Park Malaysia, \\ Malaysia
}

\begin{tabular}{l}
\hline \hline Article Info \\
\hline Article history: \\
Received Sep 14, 2019 \\
Revised Mar 7, 2020 \\
Accepted Apr 6, 2020
\end{tabular}

\section{Keywords:}

Brake failure Engine overheating Internet of Things Ultra Sonic Sensor

\begin{abstract}
One of the most important features in a car is its braking system and engine. The braking system enables the driver to control the speed of the vehicle when the need arises in order to protect the car, driver and other road users from accidents which might be fatal. The performance of the entire car also relies largely on the effective delivery and operation of the car engine whose ability to deliver the required performance is hinged on its temperature. In recent years a variety of IOT based monitoring and control systems have been explored in various areas of modern technology. This Final Year research project proposes the design and development of an IOT based vehicle brake failure and engine overheating system. The proposed system utilizes a network of sensors to monitor the temperature of the car engine, obstacles along the path of the car and the speed of the vehicle. The sensor data retrieved from the monitoring system is used by the control system consisting of a microcontroller to make decisive automatic decisions for the vehicle brake and failure system. A warning system consisting of LCD, Buzzer and LED has also been added into the system to warn the driver regarding the operation of the braking and engine overheating system. Two microcontrollers have been utilized for this research i.e. Arduino Uno for sensor data acquisition and processing and a Raspberry Pi microcontroller for purposes of sending the data wirelessly to a web platform. The web platform developed enables the user to remotely access real-time and past data from the system vehicle brake failure and engine overheating system. A variety of tests were conducted on the system to evaluate its performance whereby $95.4 \%$ accuracy was achieved in in terms of the ability of the car to effectively and automatically brake in the presence of obstacles and in terms of speed control. Testing done on the ability of the system to accurately monitor the engine temperature shows that its able to achieve $97.5 \%$ accuracy. The IOT system is able to transmit the sensor data retrieved from the system using both WIFI and mobile data whereby an average transmission time of $2.32 \mathrm{~s}$ and $4.33 \mathrm{~s}$ was recorded for each system respectively.
\end{abstract}

Copyright $(2020$ Institute of Advanced Engineering and Science. All rights reserved.

\section{Corresponding Author:}

Raed Abdulla,

School of Engineering,

Asia Pacific University of Technology and Innovation (APU),

Technology Park Malaysia, Bukit Jalil, Kuala Lumpur 57000, Malaysia.

Email: dr.raed@apu.edu.my

\section{INTRODUCTION}

Plants In the last two decades, the number of vehicles has been increased and the technology has tremendous changes which drives increment in speed. The speed plays a vital part to maintain time for longer distances. But, this speed also major problem for causes of road accidents [1]. The common braking is not sufficient for avoidance of accidents when driver is not active. Further enhancement has to be done in braking system in order to stop a car or any vehicle when driver is not able to brake. Thus, it needs automatic 
braking system. This automatic braking system allows the vehicle to brake without support of the driver [2]. In the daily life activities, accidents occur due to different reasons [3-5], one of the primary reason is brake malfunction which caused due to poor upkeep and product imperfection as well as the technical issue inside the vehicle could be another reason or because of oversight of driver [6]. Moreover, engine overheating could be happened due to several things, usually the consequence of a low coolant level or coolant loss and this may be the result of leaks in hoses, the engine or the radiator [7-8]. A faulty thermostat is another common cause of overheating, when this happen it prevent the flow of coolant from the engine to the radiator [9]. In [10] have presented braking system with distance adjustment that works automatically. The main aim of the study is to sense if there is any obstacle, vehicle or person in the road and apply the brake automatically in case of imminent collision. The approach in their study is based on sensing an obstacle that performed in 2 modes. First mode avoidance of collision, which the collision is evade evaded via auto-braking, taking immediate action. However, the driver will not be notified in this kind of system. The other system will sense the collision possibility however, would not take direct action, this system called collision mitigation. In [11] have developed an intelligent system for collision avoidance utilizing ultrasonic sensor. The main objective of the study is to control the collision or avoid the accident as well as deliver a highest safety to the driver in adverse and bad weather condition. The study utilized the IR sensor a long with the ultrasonic sensor in the vehicle, where the ultrasonic used to senses any obstacle within a predefined distance and apply the brake automatically to slow down the car. IR sensor is utilized for lane detection and accident avoidance in the right way. Furthermore, the ultrasonic sensor is attached to the car's front side to keep tracking and compute the distance between the car and obstacles. The system in [12] presents an enhancement for the automatic microcontroller that avoid collision and measure the distance of the obstacles. The system detect the obstacles and their distance using ultrasonic sensor in order to see if the car still in the safe limit or exceed the safe limit. In case, if it's exceeded the safety limit the system will apply the brakes automatically without provides warning message to the driver.

Moreover, [13] uses ultrasonic sensors along with Raspberry pi microcontroller to sense and measure moving object distance. The ultrasonic sensors are integrated to sense obstacles in front side of the car and obstacles in the vehicle's blind spot, the right and left side of the vehicle. The front, left and right sensors are connected to the Raspberry pi. The LCD display shows the distance between the vehicle and the obstacle and a buzzer and LED signal is utilized in order to warn the driver to apply the brake to prevent collision. In [14] have designed a system of robust sensors and actuators combined with a robust microprocessor to accomplish a low cost but highly reliable vehicle accident detection and prevention system using ultrasonic sensors on the front end of the vehicle. Analog proximity measurements have been taken for various collision hazards and the system will be activated at 40 kilometers per hour and above. The microcontroller is use to generate ultrasonic signal and control logic makes it possible to predict an imminent collision when the vehicle approaches an obstacle within 7 meters, this enables certain controls to provide a warning alarm and an activation signal to the automatic brake system when the collision range is reached of 5 meters. On the other hand, in [15] have developed brake failure and engine over heat indicator. The researcher aim is to design a better braking system with indicator. The system made up of two sensors. The first sensor connected to the brake shoe. The second sensor is the liner of the brake. A microcontroller receives a signal from both sensors. The sensor senses a signal to the controller when the brake shoe is alert off. The sensor sends a signal to the controller when the brake liner is cut. The microcontroller analyzes the signal and uses the indicator. It is nothing wrong, the vehicle moves and if someone is critical, the vehicle stops and the screen shows the brake failure. Since this indicates the brake status, the user can identify the brake condition and thereby reduce the chances of malfunction.

In [16] have designed and developed alarming system to avoid engine over heat. The aim of this research is to develop such an automatic control system for an engine that will help protect the engine against overheating by means of a temperature sensor alarm and signal. This signal and alarm system consists mainly of a temperature sensor, microcontroller and LCD circuit. The temperature sensor is attached to the engine and the temperature sensor is utilized to sense the temperature, read and send it to the control board. Arduino microcontroller is utilized to automatically control the entire system, which reduces design and control complexity.

In the era of industrial revolution 4.0, merging existing and new technology with the Internet of Things (IoT) system, offer the beneficial impact [17-22]. An IOT based vehicle emergency and tracking system was presented by [23]. The system proposed in this research consisted of three main parts, the vehicle and ambulance unit, the traffic unit and finally the main webserver. The traffic control system was used for monitoring the signal posts along the path of the ambulance using an RFID reader whereas the vehicle unit was used to sense if the ambulance was involved in a car accident using an ADXL accelerometer for sensing the car vibrations. In [24] AN IOT based vehicle monitoring system consisting of Bluetooth technology has been proposed. The system developed was used to monitor various parameters within the vehic68e such as 
temperature, speed, engine revolutions, vehicle GPS position and the car tilt angle in relation to the horizontal axis. An 8051 microprocessor was used as the main microcontroller for the system which operates at $11.0592 \mathrm{MHz}$ with a crystal rating of up to $40 \mathrm{MHz}$ whereas a low energy Bluetooth module was used to transmit and receive the data wirelessly. In [25] proposed the implementation of an IOT based vehicle alert and tracking system. The embedded hardware proposed in this research consisted of an Arduino Uno R3 as the main control board due to its cheap price, low power requirements and multiple I/O pins for connecting sensors and other hardware. The monitoring system consisted of a SW420 vibration sensor for car collision detection, a HX711 load sensor for car seat driver detection and a GPS sensor consisting of a Neo7N module to provide position data of the car. An internet router was employed to provide a low cost internet gateway for publishing data using MQTT protocol.

In summary, the experimental results have been shown that automatic braking systems using ultrasonic sensor are effective and can reduce the collisions on roads, which will reduce the number of death. Thus, different researchers have utilized the ultrasonic sensor as a tool for braking failure system during the past two decades. The aim of this research is to design and develop an experimental model that can be automatically minimize the break failure and control engine overheating by utilizing ultrasonic sensor and temperature sensor, while the objectives of this research: To develop and implement a car brake failure and engine overheating system, to develop a control and monitoring unit consisting of a network of sensors and embedded hardware system, to develop an IOT based system for remote monitoring of the car brake failure and engine overheating system and finally to test and analyze the performance of the developed system.

\section{RESEARCH METHOD}

In this research, the proposed methodology is divided into different stages. An overview on the approach used is shown in the block diagram Figure 1. The vehicle brake failure and engine overheating system uses an Arduino Uno microcontroller to retrieve data from the sensor network consisting of the ultrasonic sensor, temperature sensor and two speed sensors located on the left and right side of the vehicle. The braking system implemented in this research consists of two DC motors located on the left and right side of the vehicle whose speed and direction of rotation is controlled with the aid of a L298N H-bridge motor driver as shown in Figure 1. The L298N H-bridge driver consists of a simple circuit consisting of four switching elements with a centered load that allows the DC motors to be mounted and controller based on pulse width modulation (PMW) signals generated from the Arduino Uno microcontroller. In order to alert the driver in terms of brake failure and engine overheating, a $16 \times 2$ liquid crystal display (LCD) unit connected to a i2c communication module was used. The $\mathrm{i} 2 \mathrm{C}$ bus was used to connect the LCD directly to the Arduino to minimizing the amount of connection wires required i.e. the i2c utilizes only two pins for two signals i.e. SDA for data signals and SCL for clock signals as shown in Figure 2.

In order to ease the connection and integration of the various sensors and actuators with the microcontroller, a PCB board was used which involved the soldering of the pins on a centralized location for easy connection and troubleshooting. A temperature sensor consisting of a NTC thermistor was used to monitor the temperature of the engine. The thermistor used is basically a resistance thermometer whose internal resistance varies directly with temperature and can be used for measuring a wide range of temperatures i.e. $-260^{\circ} \mathrm{C}$ to $850^{\circ} \mathrm{C}$ in comparison to conventional temperature sensors like DHT 11 i.e. $-20^{\circ} \mathrm{C}$ to $100^{\circ} \mathrm{C}$. In order to monitor the speed of the vehicle, a speed sensor consisting of an LM393 module was used. The LM393 speed sensor is a sensor that produces processed pulse trains when the path of its optical vision is interrupted physically by an encoder circuit of and optical sensor.

The alert system used for the vehicle brake failure and engine overheating system consisted of a buzzer and LED. The buzzer used for the implemented system produces an audio signal consisting of a beep to alert the driver when the engine temperature exceeds the threshold set in the Arduino program. In order to power up the system, an $8 \mathrm{~V}$ battery system consisting of a Lipo rechargeable battery was used. The IOT system implemented for remote monitoring of the vehicle brake failure and engine overheating system consists of a Raspberry pi 3 microcontroller and an MCP3008 chip. The Raspberry pi 3 microcontroller was used to transmit the data retrieved from the sensors to an IOT cloud using internet connection, whereas the MCP3008 chip was used for analog to digital conversion of the analog sensors used for the system i.e. NTC thermistor. 


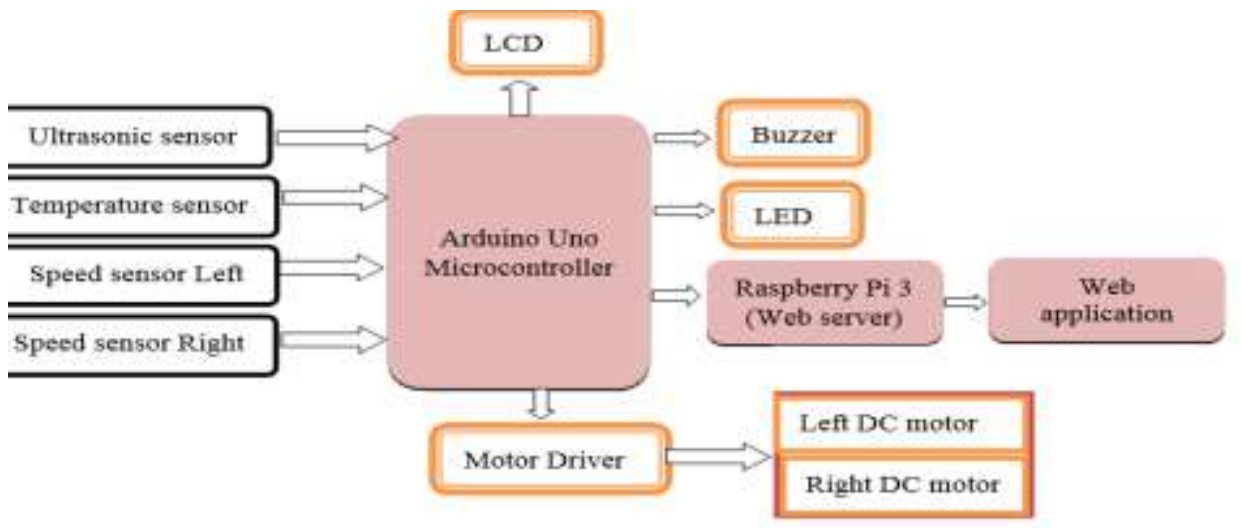

Figure 1. Blcok of the proposed methodology

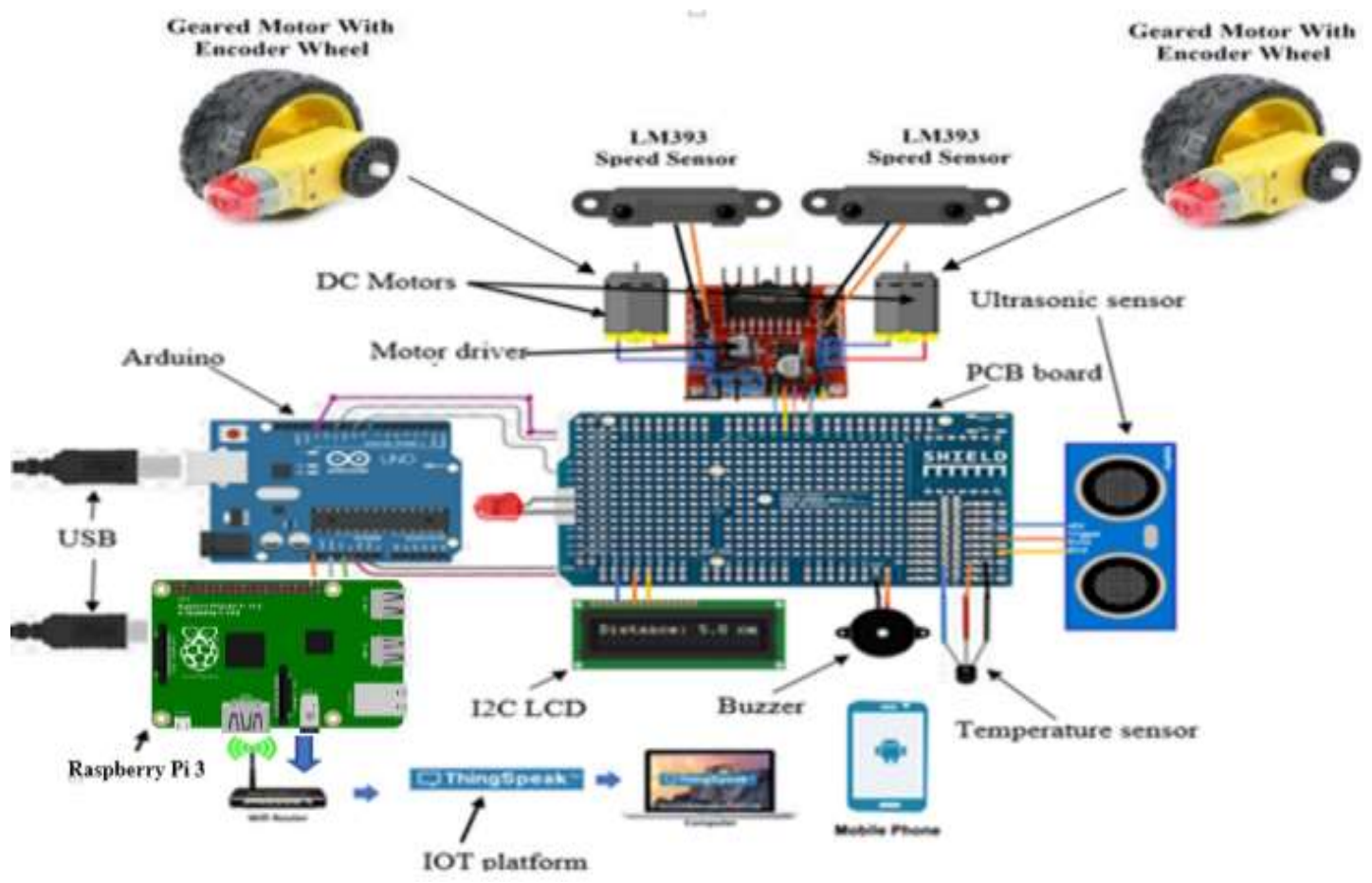

Figure 2. Circuit diagram

\subsection{Proposed Car Method}

The construction of the vehicle system implemented in this research was done with the aid of sustainable acrylic materials and recycled cardboard. The electronic circuit, microcontroller, PCB board and sensors were mounted onthe acrylic board measuring $22.5 \mathrm{~cm}$ by $10.2 \mathrm{~cm}$ by $0.35 \mathrm{~cm}$. A separate acrylic box measuring $16.2 \mathrm{~cm}$ by $8.7 \mathrm{~cm}$ by $5.8 \mathrm{~cm}$ was made to house the IOT system consisting of the Raspberry pi 3 microcontroller and an MCP3008 chip as shown in Figure 3. A switch was mounted on top of the box to control the switching on and off the vehicle system. An ON/OFF switch shown in Figure 4 was added to the design to enable the system to have a centralized switch for controlling the entire system.

\subsection{Vehicle Brake Failure and Engine Overheating Control System}

The vehicle brake and engine failure system was used to monitor the operation of the vehicle brake failure and engine overheating system in terms of obstacle/speed monitoring and engine temperature respectively. In order to achieve this, a temperature sensor was used to collect temperature readings from the engine whereas a speed sensor was used for speed monitoring and finally an ultrasonic sensor was used for obstacle detection as shown in Figures 5,6 and 7. According to the flowchart in Figure 5, the system 
checks the distance between the vehicle and the obstacle i.e. either another car or pedestrian based on the distances shown in the flowchart, whereby an alert warning message is displayed on the LCD and the LED blinks if the conditions stated are met. When the distance between the obstacle and the vehicle is between 21 and $30 \mathrm{~cm}$, a warning message "warning Obstacle, slowing Down" is displayed on the LCD and the red LED blinks after every 3 seconds, whereby the speed of the vehicle is lowered to 150 r.p.m if the driver does not slow down. In addition, when the distance is further reduced between the vehicle and the obstacle i.e. between $15 \mathrm{~cm}$ and $20 \mathrm{~cm}$, a warning message "warning slow Down" is displayed on the LCD and the red LED blinks after every 1 second, whereby the speed of the vehicle is further reduced to 80 r.p.m if the driver does not slow down. However, if the distance between the vehicle and the obstacle is further reduced i.e. less than $10 \mathrm{~cm}$, a warning message "Emergency Car Stop" is displayed on the LCD and the red LED blinks stops blinking and the speed of the vehicle is gradually reduced to 0 r.p.m i.e. car stops moving if the driver does not slow down.

In terms of the engine heat monitoring system illustrated in the flowchart in Figure 8, the thermistor sensor obtains the temperature of the engine modelled using a lighter. If the temperature of the engine is between 27 and $30{ }^{\circ} \mathrm{C}$, a warning message "WARNING engine heating Up" is displayed on the LCD and the Buzzer beeps after every 2 seconds until the engine temperature is lowered. However, if the car engine temperature exceeds $32^{\circ} \mathrm{C}$, a warning message "Engine Too hot, Engine Shutdown" is displayed on the LCD, the Buzzer stops beeping and the car is brought to a gradual stop.

The Vehicle brake failure system relies on the speed sensor and ultrasonic sensor readings to make the important decision of either reducing the speed of the car or stopping it; and consequently sending alert warnings using the LCD and LED blinking. The speed sensor consistently checks the speed of the car periodically whereby if the speed of the car exceeds the set threshold of 160 r.p.m, a warning is displayed on the LCD i.e. "DANGER SLOW DOWN" to warn the driver that the car is moving at a very high speed as shown in Figure 8. However, If the speed is between the range of 160 and 165 r.p.m, a warning message appears on the LCD to warn the driver to reduce the speed as shown in Figure 7.

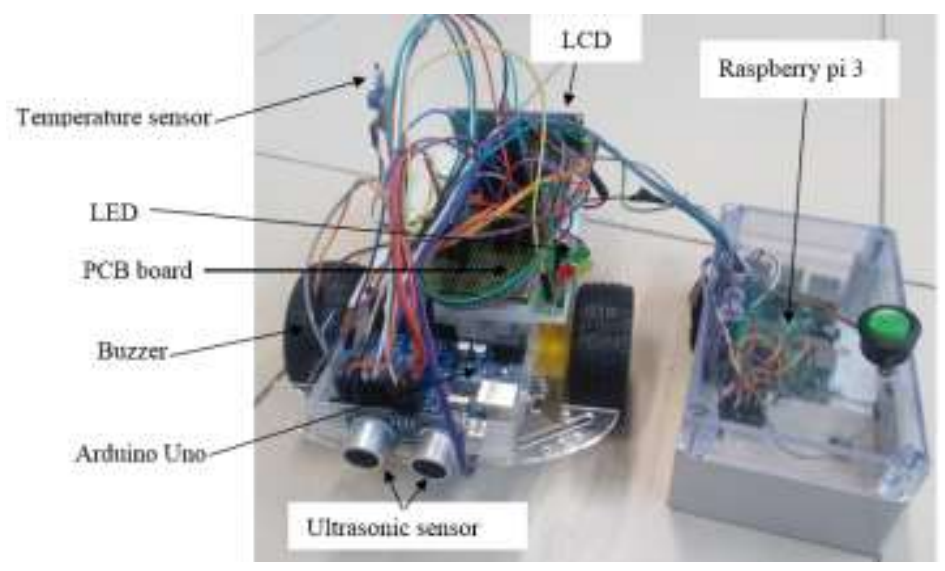

Figure 3. Overall system model

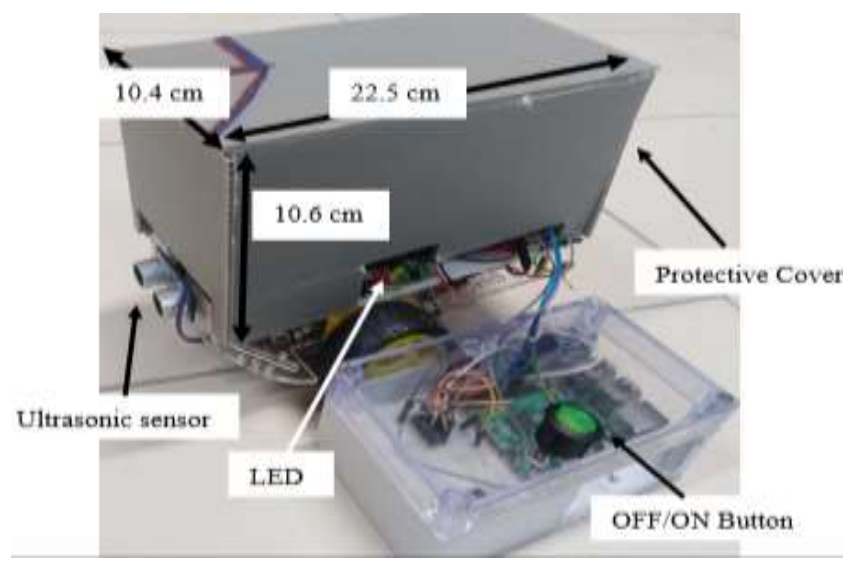

Figure 4. Vehicle system front Side view with protective cover 


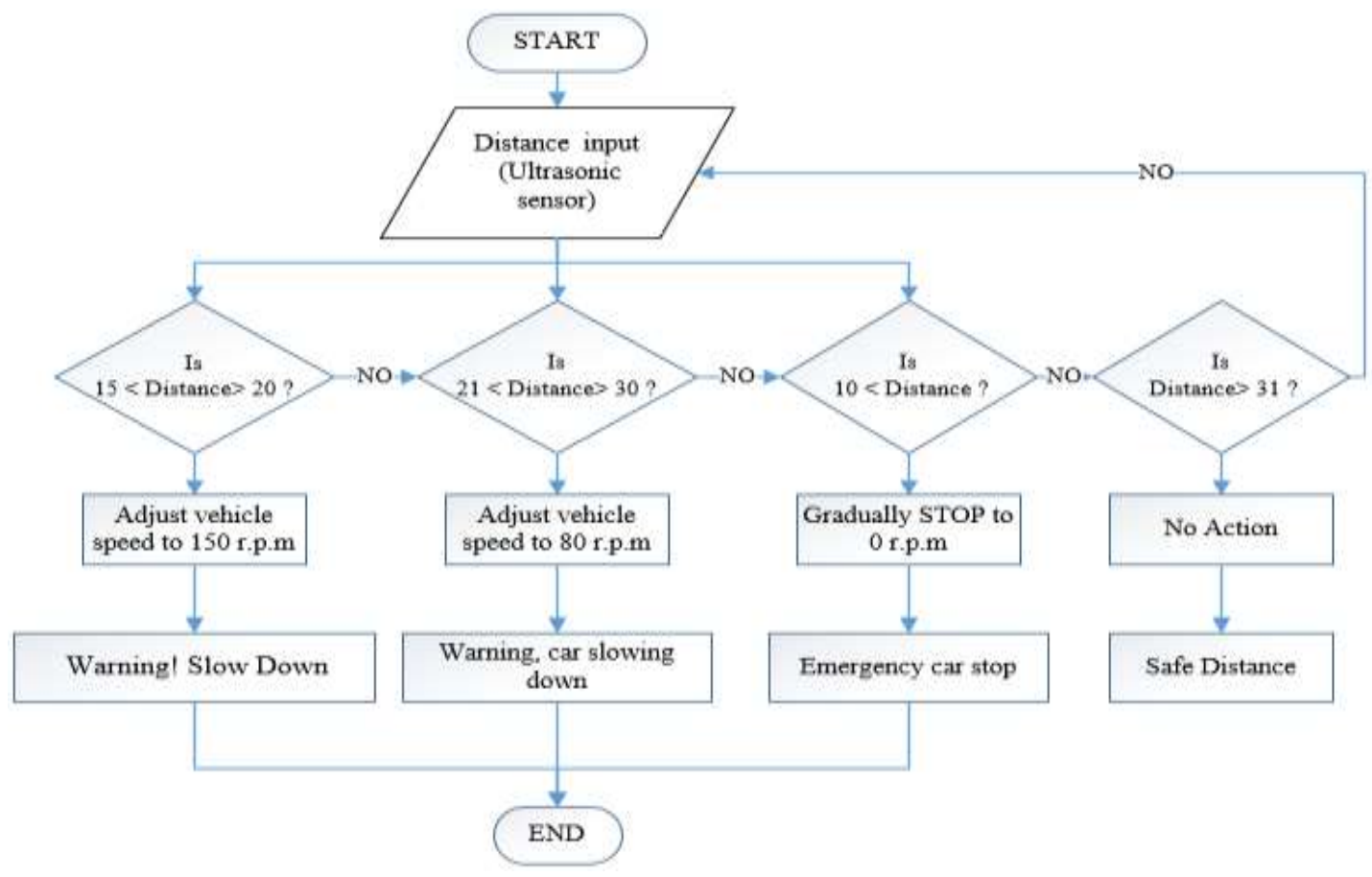

Figure 5. Obstacle detection unit

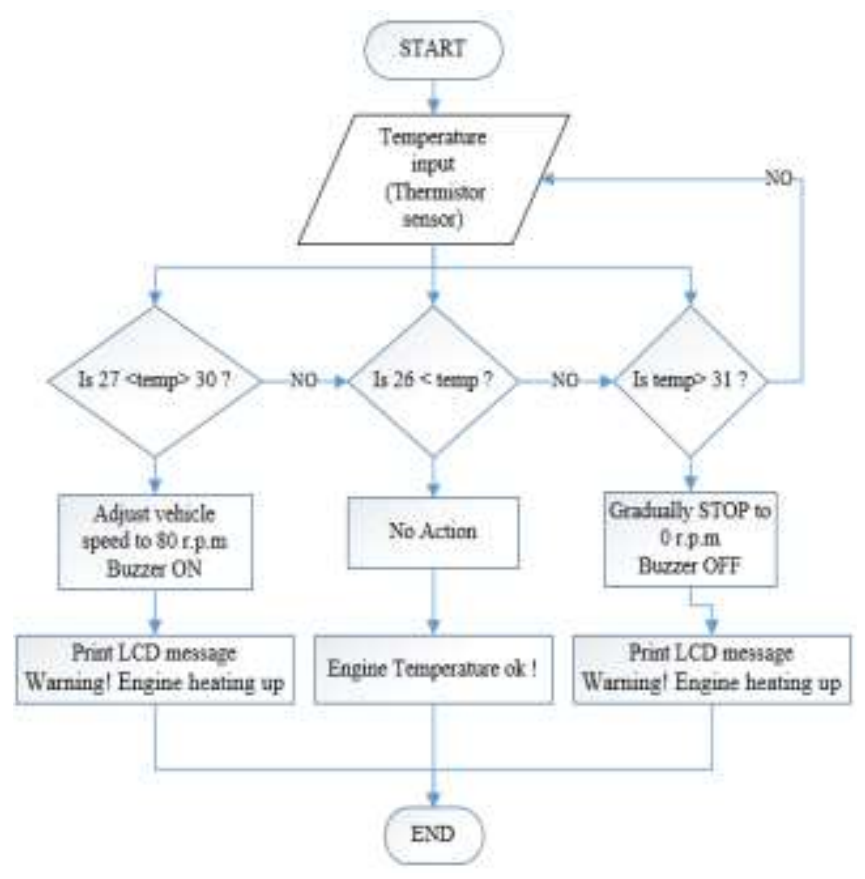

Figure 6. Temperature unit flow chart

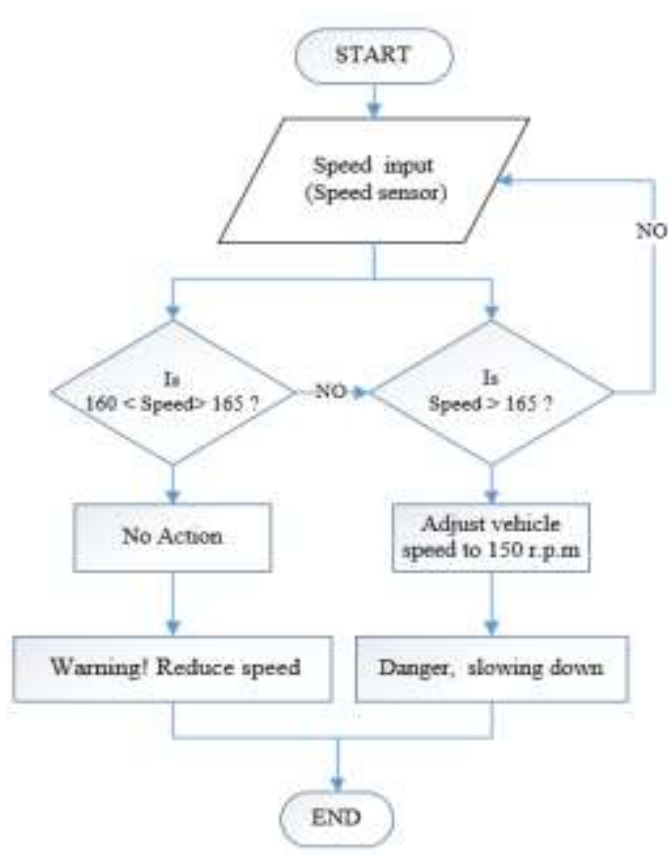

Figure 7. Speed unit flowchart

\section{EXPEREMNTAL RESULTS}

In The IOT based vehicle brake failure and engine overheating system implemented for this reserach was tested under various conditions whereby the simulation and hardware results obtained were documented. The results obtained from implementation of the embedded hardware system is as shown in Table 1. The results were tabulated based on the controlled speed of the vehicle and the warning messages from the buzzer, led and LCD.The results obtained from implementation of the IOT system is as shown in Figure 8. 
The results illustrated in Figure 8, show that the system is able to accurately measure the temperature of the car engine and send it to the IOT cloud as shown in the graphs plotted on the Thing speak platform. In addition, the speed of the vehicle from both wheels i.e. motor speed 1 and motor speed 2 is also transmitted wirelessly to the IOT dashboard. A gauge system was used to show the engine temperature, whereby a red scale was defined to show when the engine was overheating. The following test has been carried out to analyze the performance of the proposed system.

Table 1. Embedded hardware results

\begin{tabular}{ccc}
\hline Sensor reading & Control (r.p.m) & Warning message \\
\hline Ultrasonic: $21.5 \mathrm{~cm}$ & 81.3 & Warning, car slowing down \\
Ultrasonic: $28.7 \mathrm{~cm}$ & 80.3 & Warning, car slowing down \\
Ultrasonic: $19.3 \mathrm{~cm}$ & 150.2 & Warning! Slow down \\
Ultrasonic: $15.7 \mathrm{~cm}$ & 151.4 & Warning! Slow down \\
Ultrasonic: $2.1 \mathrm{~cm}$ & 0 & Emergency, car Stop \\
Ultrasonic: $0 \mathrm{~cm}$ & 0 & Emergency, car Stop \\
Speed: 163.4 r.p.m & No action & Warning! Reduce speed \\
Speed: 160.5 r.p.m & No action & Warning! Reduce speed \\
Speed: 177.3 r.p.m & 150.8 & Danger, slowing down \\
Speed: 200.3 r.p.m & 151.1 & Danger, slowing down \\
Temperature: $25.4^{\circ} \mathrm{C}$ & 80.4 & Warning! Engine heating up \\
Temperature: $27.5^{\circ} \mathrm{C}$ & 80.3 & Warning! Engine heating up \\
Temperature: $25.5^{\circ} \mathrm{C}$ & No action & Engine temperature ok! \\
Temperature: $31.6^{\circ} \mathrm{C}$ & 0 & Engine too hot, Engine shutdown \\
Temperature: $34.3^{\circ} \mathrm{C}$ & 0 & Engine too hot, Engine shutdown \\
\hline
\end{tabular}
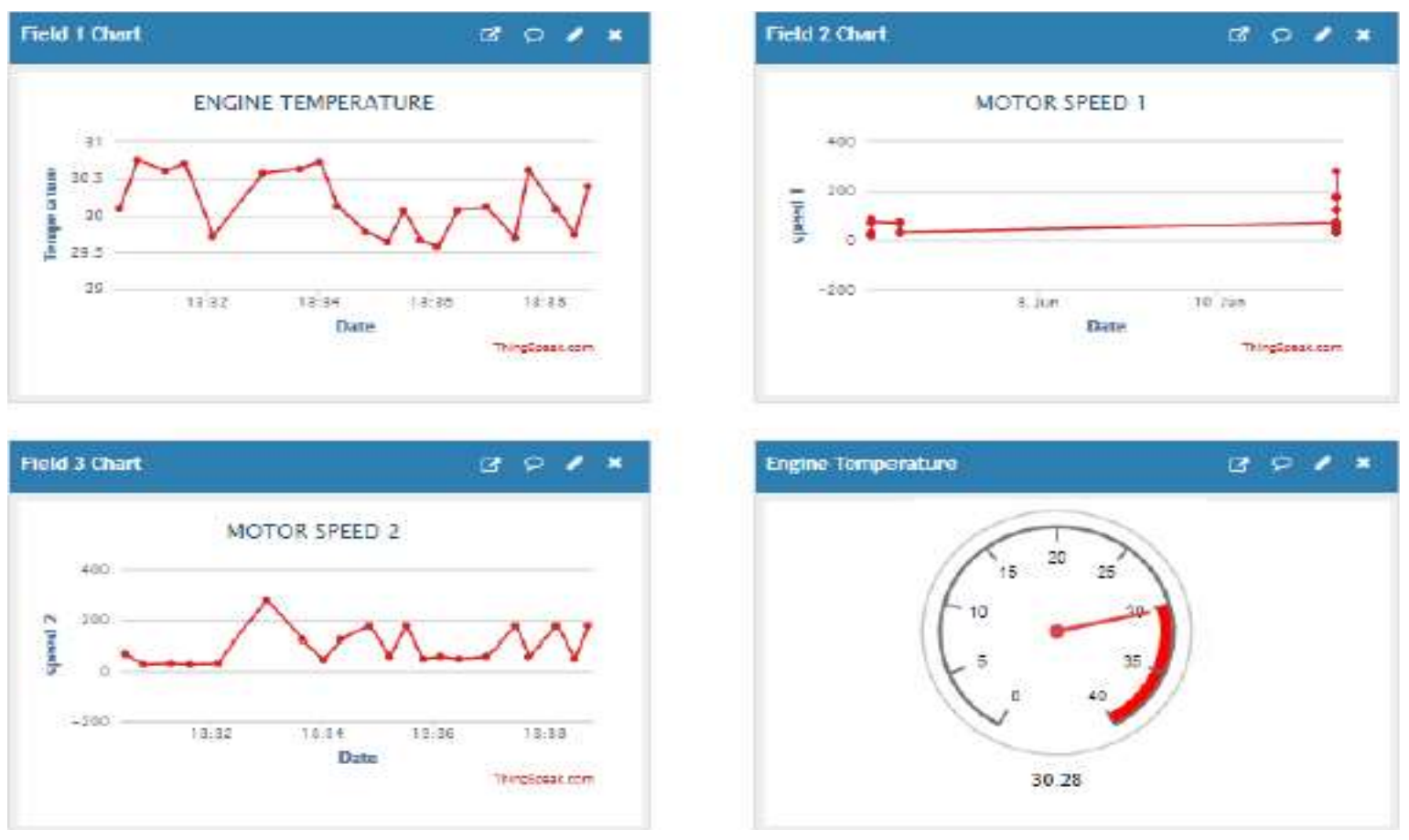

Figure 8. Engine temperature and graphs

\subsection{Braking System Test Based on Obstacle Detected}

A braking system test was conducted based on obstacles detected along the path of the vehicle. This test was done to identify the ability of the braking system to identify an obstacle along the path of the vehicle at different distances and take the appropriate action i.e. by displaying warning messages on the LCD and controlling the speed of the motor. The data collected from the obstacle detection test illustrated that the system was able to accurately detect obstacles along its path of motion and take the appropriates actions by adjusting the speed of the vehicle when no action is taken by the driver. However, a slight deviation between the theoretical and experimental values was observed during testing. This slight deviation in results was mainly due to the delay in relay of signals sent between the microcontroller and the L298N motor driver once the 
sensor readings are received and interpreted by the Arduino microcontroller. It was also observed that as the distance between the obstacle and the vehicle increased, the speed of the vehicle was gradually reduced to zero for distances less than $10 \mathrm{~cm}$ as shown in Figure 9.

\subsection{Braking System Test Based on Speed of the Vehicle}

In this test, two LM393 speed sensors positioned at both wheels of the vehicle model developed were used to measure the speed of the vehicle using an encoder whereas an L298N motor driver was used to control the speed of the wheels based on the control signals received from the Arduino Uno microcontroller. A $16 \times 2$ LCD was also used to display the warning messages for the driver to take action as well as the actions taken by the vehicle brake failure system. It was observed from the graph plotted for the Controlled speed against actual vehicle speeds that as the speed of the vehicle increases beyond the set threshold of 165 r.p.m the speed is reduced back to $150 \pm 1.2$ r.p.m as shown in Figure 10 .

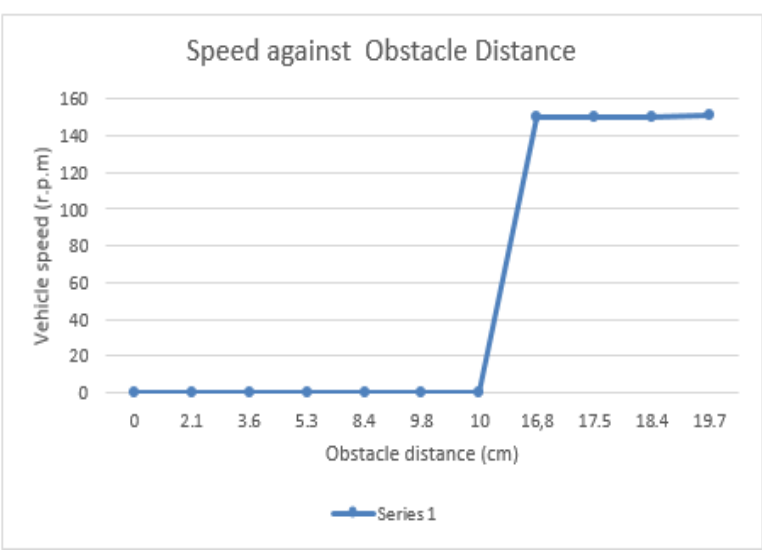

Figure 9. Vehicle speed against obstacle distance

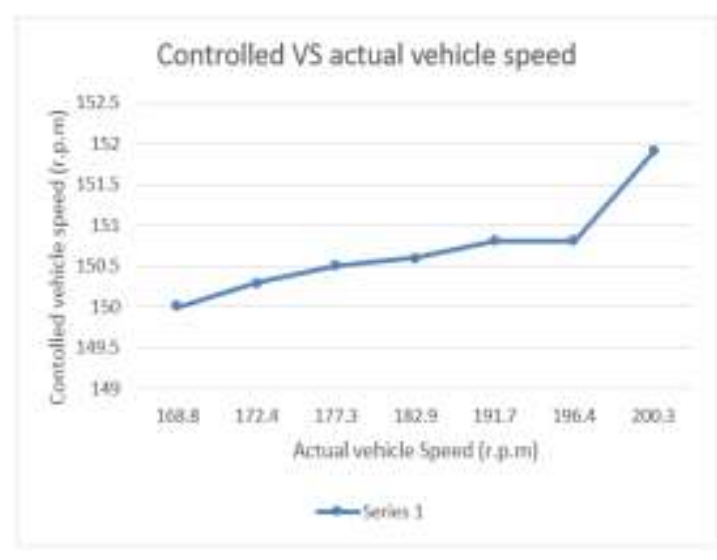

Figure 10. Controlled against actual vehicle speeds

\subsection{Engine Overheating Test}

An engine overheating test was conducted to verify the ability of the system in identifying, evaluating various engine temperatures and thereby taking the appropriate action i.e. by displaying warning messages on the LCD or by gradually slowing down the car and shutting down the engine. A thermal sensor module consisting of an NTC thermistor was used to measure the temperature of the engine which was modelled using an independent heat source. An L298N motor driver was used to control the motion of the car based on the temperature thresholds and control signals received from the Arduino Uno microcontroller. A graph of engine temperature against vehicle speed was plotted as shown in Figure 11, whereby it was observed that as the temperature of the engine increased from $31.6^{\circ} \mathrm{C}$ to $33.2{ }^{\circ} \mathrm{C}$ the speed of the vehicle was gradually reduced to 0 r.p.m, whereas as the temperature reduced, the speed of the vehicle increased.

\subsection{Overall Vehicle Brake Failure and Engine Overheating Test}

An Overall vehicle brake failure and engine overheating test was conducted to evaluate the performance of the integrated system after conducting individuals test on each part. The individual parts of the system were all integrated together to form the final design of the vehicle brake failure and engine overheating system. The temperature, distance and speed sensors were used to collect vehicle data using the Arduino Uno microcontroller. The engine temperature was varied using heat source whereas a cardboard was used to model an obstacle i.e. vehicle or pedestrian. 


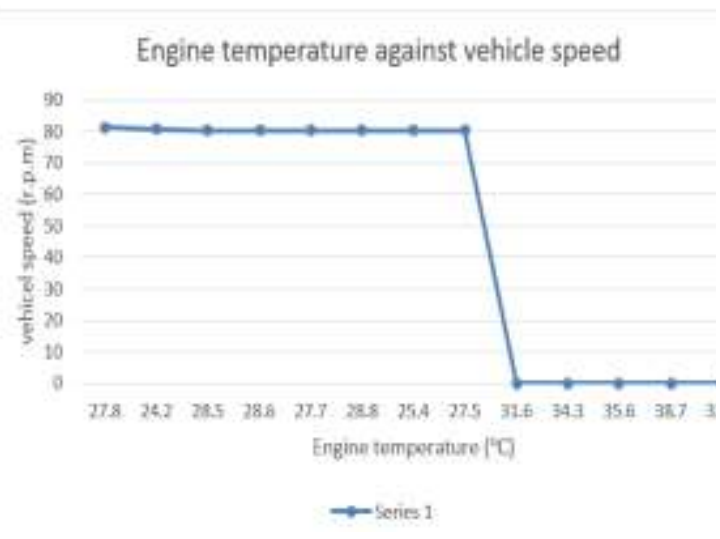

Figure 11. Engine temperature against vehicle speed

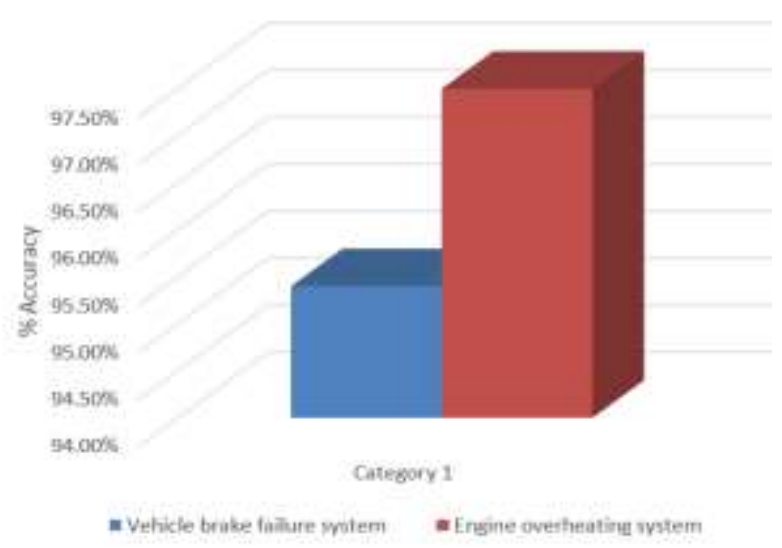

Figure 12. Overall vehicle brake failure and engine overheating test results

\section{CONCLUSION}

In this paper, integrate for car brake failure and engine overheat system system has been designed, developed and implemented. The vehicle brake failure implemented has the ability to control the motion of the car based on the speed of the vehicle and the proximity of an obstacle identified with the aid of a speed and distance sensor along its path of motion respectively, whereby alert messages are displayed on an LCD for the driver to take action before the automatic system does. The engine overheating system monitors the temperature of the engine whereby once a temperature threshold is achieved warning messages are displayed on an LCD whereby the car is brought to a gradual stop if the driver does not take action

Moreover, a variety of tests were conducted on the system to evaluate its performance whereby $95.4 \%$ accuracy was achieved in in terms of the ability of the car to effectively and automatically brake in the presence of obstacles and in terms of speed control. Testing done on the ability of the system to accurately monitor the engine temperature shows that its able to achieve $97.5 \%$ accuracy. The IOT system is able to transmit the sensor data retrieved from the system using both WIFI and mobile data whereby an average transmission time of $2.32 \mathrm{~s}$ and $4.33 \mathrm{~s}$ was recorded for each system respectively.

\section{REFERENCES}

[1] BK RH, Pooja P, Chaithra M, Megha S, “Automatic Braking System for Automobiles Using IR Sensor," Int. J. Adv. Res. Electr. Electron. Instrum. vol. 5, no. 5, p. 4343.2016.

[2] Ashwini A. Kamble, Vishal Nalawade, S. S. PATIL. Automatic Braking System, International Journal of Advance Research, Ideas and Innovations in Technology, www.IJARIIT.com.

[3] V. Chand and K. J, "RFID-GPS based mechanism using aodvrp for stolen vehicle detection in vanet," Indonesian Journal of Electrical Engineering and Computer Science, vol. 18, no. 1, p. 396, Jan. 2020.

[4] M. Z. A. Razak, S. S. M. Fauzi, R. A. J. Gining, and M. N. F. Jamaluddin, "Data visualisation of vehicle crash using interactive map and data dashboard," Indonesian Journal of Electrical Engineering and Computer Science, vol. 14, no. 3, p. 1405, Jan. 2019

[5] M. K. Abbas, T. J. Low, and R. Abdulla, "Automated Fining System for High Speed Driving Offences via VANET," 2019 International Conference on Green and Human Information Technology (ICGHIT), 2019.

[6] Maske, R., Surwase, S., Moharir, B. Mahajan. V., Kedar. Adkine, A, "Automatic brake failure indicator and braking system," International Journal of Advance Research and Innovative Ideas in Education, 2395-4396. 2017

[7] G. S. Missan and I. P. Keswani, "Analysis of Causes of Engine Overheating due to Cooling System Failure Using Pareto Principle," International Journal of Engineering Trends and Technology, vol. 36, no. 5, pp. 242-248, 2016.

[8] J. Wodecki, P. Stefaniak, A. Michalak, A. Wyłomańska, and R. Zimroz, "Technical condition change detection using Anderson-Darling statistic approach for LHD machines - engine overheating problem," International Journal of Mining, Reclamation and Environment, vol. 32, no. 6, pp. 392-400, 2017.

[9] C. S. Mishra, F. Ali, and S. Adam, "Study of the causes of engine failure in ship and maintenance required to prevent engine failure," International Journal of Contemporary Research and Review, 2017.

[10] G. Agrawal, M. Chauhan, H. Sinha, "Automatic Braking System with Distance Adjustment," Indian Journal of Applied Research Science, vol. 14, no. 2, pp. 502-505, 2017.

[11] C. Anusha, P. Venkataratnam, "Collision Control and Collision Avoidance Using Ultrasonic Sensor," International Journal of Current Engineering and Scientific Research (Ijcesr), vol. 2, no. 7, pp. 204-206. 2015. 
[12] A. Aliyu, J. G. Kolo, O. O. Mikail, J. Agajo, B. Umar, and O. I. Aguagba, “An ultrasonic sensor distance induced automatic braking automobile collision avoidance system," 2017 IEEE 3rd International Conference on ElectroTechnology for National Development (NIGERCON), 2017.

[13] Garethiya. S, et al., "Predictive vehicle collision avoidance system using Raspberry-pi," ARPN Journal of Engineering and Applied Sciences, vol. 10, no. 8, pp. 32-34. 2015.

[14] Y. L. Chen and W. J. Lee, "Safety distance warning system with a novel algorithm for vehicle safety braking distance calculating," International Journal of Vehicle Safety, vol. 5, no. 3, p. 213, 2011.

[15] Venkatachalapathi. N, Mallikarjuna. V, “Automatic Brake Failure Indicator and Over Heating Alarm,” International Journal of Engineering Science and Computing, p.3. 2016.

[16] M.S. Akther Momin, et al., "Automatic Signal and Alarming System to Avoid Engine Overheating. International Journal of Research, vol. 3, no. 13. 2016.

[17] Z. Dzulkurnain, A. K. Mahamad, S. Saon, M. A. Ahmadon, and S. Yamaguchi, "Internet of things (IoT) based traffic management \& routing solution for parking space," Indonesian Journal of Electrical Engineering and Computer Science, vol. 15, no. 1, p. 336, Jan. 2019.

[18] R. Abdulla, A. Abdillahi, and M. K. Abbas, "Electronic Toll Collection System based on Radio Frequency Identification System," International Journal of Electrical and Computer Engineering (IJECE), vol. 8, no. 3, p. 1602, Jan. 2018.

[19] M. O’Neill, “Insecurity by Design: Todays IoT Device Security Problem,” Engineering, vol. 2, no. 1, pp. 48-49, 2016

[20] I. Lee and K. Lee, "The Internet of Things (IoT): Applications, investments, and challenges for enterprises," Business Horizons, vol. 58, no. 4, pp. 431-440, 2015.

[21] D. D. Patil, et al., "Car Accident Detection and Car Health Monitoring using IoT," International Journal of Research in Engineering, Science and Management, vol. 2, no. 4, pp. 22-26. 2019.

[22] H. J. Dong, R. Abdulla, S. K. Selvaperumal, S. Duraikannan, R. Lakshmanan, and M. K. Abbas, "Interactive on smart classroom system using beacon technology," International Journal of Electrical and Computer Engineering (IJECE), vol. 9, no. 5, p. 4250, Jan. 2019.

[23] G. Patole, j. Shide, S. Salve, R. Vipul, S Puri," S IOT based Vehicle Tracking \& Vehicular Emergency System- A Case Study and Review," International Journal of Advanced Research in Electrical, Electronics and Instrumentation Engineering, vol. 6, no. 10, pp. 8001-8006. 2017.

[24] J. Ashita, et al., "IoT based Vehicle Monitoring System using Bluetooth Technology," International Journal of Innovative Research in Science, Engineering and Technology, vol. 6, no. 3, pp. 4778-477. 2017.

[25] N. Sarasvathi, F. Jason, "Study and Implementation of Internet of Things (IoT) Based Vehicle Safety Alert and Tracking System,” Journal of Intelligent Control and Automation, vol. 2, no. 3, pp. 123-125. 2017.

\section{BIOGRAPHIES OF AUTHORS}
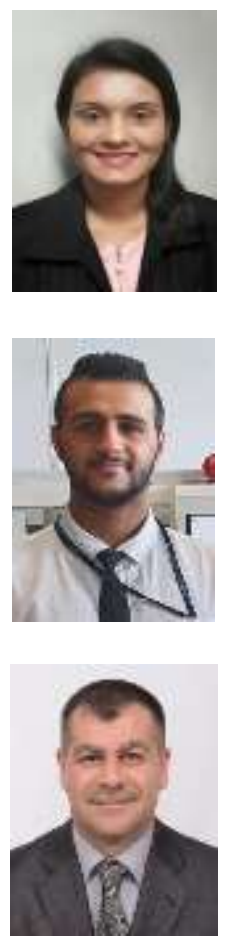

Subhashini Gopal Krishnan Subhashini Gopal Krishnan received the Bachelor's degree in Electrical and Electronics Engineering from University Tenaga Nasional, in 2009, the Master degree in Engineering Management from University Tenaga Nasional, in 2011. He is currently a Lecturer at the School of Engineering, Asia Pacific University of Technology and innovation (APU) in Bukit Jalil, Kuala Lumpur, Malaysia. She has contributed in research and in the areas of renewable energy, sustainable development and engineering management. Her research output was translated to numbers of awards and publications. She is also a Chartered Engineering in the institution of Mechanical Engineers.

Anas Albanna was born in Amman, Jordan, in 1996. Anas Albanna - obtained his B. Eng degree (with honors) in Mechatronic Engineering from Asia Pacific University of Technology and Innovation, Malaysia in 2019. His research interests focus on Artificial Intelligence, Image Processing, Machine Learning, Internet of Things, Machine Vision, Robotics and Automation.

Dr. Raed Mohammed Taher Abdulla received the Bachelor's degree in Electrical engineering from AL-Mustansiria University, Baghdad, Iraq in 1997, the Master degree in Electronic Systems Design Engineering from Universiti Sains Malaysia, Malaysia in 2008 and he received his PhD in Wireless and Mobile Systems from Universiti Sains Malaysia, Malaysia in 2012. He is currently a Senior Lecturer at the School of Engineering, Asia Pacific University of Technology and innovation (APU) in Bukit Jalil, Kuala Lumbur, Malaysia. He has contributed in research and in the areas of Radio Frequency Identification (RFID) and Wireless Sensor Network (WSN). His research output was translated to numbers of awards and publications. He is a member in the institution of engineering and technology (IET). Dr. Raed also member in Centre of Research and Development of IoT (CREDIT), Asia Pacific University of Technology and Innovation (APU). 